\title{
Acute respiratory infection: first clinical manifestation of active infection with cytomegalovirus in HIV patients presenting to the emergency department
}

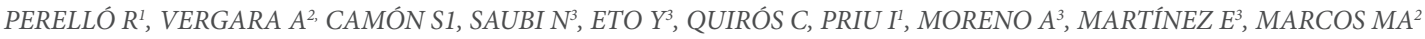 \\ ${ }^{1}$ Emergency Department, Hospital Clínic, Barcelona, Spain \\ ${ }^{2}$ Microbiology Department, Hospital Clínic, Centro de investigación internacional (CRESIB) Hospital Clínic, Universidad de Barcelona, Barcelona, Spain \\ ${ }^{3}$ Infectious diseases, Hospital Clinic, IDIBAPS, Universidad de Barcelona, Barcelona, Spain
}

Correspondig author:

Perelló $R$

Emergency Department

Hospital Clinic

C/Villarroel 170, Barcelona, Spain

Phone: +34932275400 (ext 4031)

E-mail: rperello@clinic.cat

\section{ABSTRACT}

Introduction. Traditionally, digestive and ophthalmic symptoms have been described as predominant in the clinical presentation of active infection with cytomegalovirus (AICMV). Nevertheless, it seems that this has changed following the introduction of antiretroviral therapy (ART). Nowadays, respiratory infection (RI) in HIV-infected patients is the first reason for consulting an Emergency Department (ED). Among these patients, the mortality is important.

Aim. To determine if RI in HIV-infected patients is a common manifestation of AICMV and to describe the changes in clinical presentation of AICMV in relation to what was previously described.

Methods. A single-center, retrospective study was conducted over the duration of nine years (2005-2015). All HIV patients who consulted our emergency department with respiratory symptoms and were diagnosed with AICMV were included. Isolation of other co-infecting microorganisms and mortality in the series are also described.

Results. 56 HIV-infected patients with AICMV were identified. RI was diagnosed in $34(61 \%), 31(91 \%)$ patients had pneumonia and 3(9\%) pulmonary tuberculosis. The most frequently isolated microorganism was P. jirovecii, in 21 (68\%) patients.
Bacteria were isolated in five patients (15\%). Five patients died from RI (9\%). No patient had acute retinitis or any other ophthalmic involvement.

Conclusion. Clinical manifestation of AICMV in HIV patients has changed, and RI is the most common manifestation, caused by opportunistic microorganisms with $9 \%$ mortality.

Key words: HIV, infection respiratory, pneumonia, $C M V$

\section{INTRODUCTION}

Human cytomegalovirus (CMV) infection is highly prevalent in the world, especially in developing countries where $90 \%$ of the population is infected with this virus, while infection is estimated at $60 \%$ in developed countries. (1) In immunocompetent individuals, the infection is usually asymptomatic, mild or causes a mononucleosis syndrome but in immunosuppressed patients it behaves as an opportunistic pathogen, causing severe damage. (2)

Specifically in HIV-infected patients with severe immune suppression, it manifests in up to $40 \%$ of them throughout their life, usually as ophthalmic manifestations or digestive. (3) However, following the introduction of combination antiretroviral therapy (cART), prognosis has improved, and consequently active infection with cytomegalovirus (AICMV) has decreased. (4)

Respiratory infection (RI) is one of several indicators of AICMV, and the main cause for attending an Emergency Department (ED) in HIV-infected patients. Community-acquired pneumonia is the leading cause of death in these patients. (5) Although the incidence of RI has decreased, and its etiology has changed due to the introduction of cART, it has a non-negligible mortality and often requires admission to an intensive care unit (ICU). (6)

The study objectives were to clarify, in a cohort of HIV-infected patients, if the usual clinical manifestations of AICMV have changed, and if RI has an important role in the presentation of AICMA, Furthermore, we wanted to find out which microorganisms cause it, and what the 30-day mortality is.

\section{METHODS}

\section{Design, setting, and population}

This is a single-center retrospective study taking place during the course of nine years (2006-2015) and performed at our hospital which conducts annual monitoring of $5000 \mathrm{HIV}$-infected patients. All patients with HIV infection who attended our ED with respiratory symptoms and were diagnosed with AICMV were included. 


\section{Study protocol}

AICMV was defined as the isolation of the virus or evidence of CMV replication, regardless of symptoms, by polymerase chain reaction (PCR); culture in any fluid or body tissue; and CMV disease, where the infected patient, besides virus replication, shows symptoms or signs of disease (viral syndrome or visceral involvement). $(7,8)$ For the diagnosis of pneumonia, regardless of etiology, the criteria of the Infectious Diseases Society of America were applied. (9) Severe immunosuppression was defined as the presence of a CD4 count of less than 200 cells/ $\mu \mathrm{l}$ in blood.

\section{Measurements}

The following epidemiological, clinical and laboratory variables were collected from patients: sex, age, previous opportunistic infections, associated comorbidities, route of HIV transmission, toxic habits, cART, number of CD4, CD8 lymphocytes and HIV viral load (VL) (prior to admission), coinfection with hepatitis $\mathrm{C}$ virus (HCV), target organ of CMV infection, presence of fever, need for mechanical ventilation (MV), number of total leukocytes, platelets, hemoglobin, liver profile, ICU admission, and 30-day mortality.

To determine the presence of pathogens, the results of blood cultures (Bactec 9240; Becton Dickinson), Gram stain and culture of respiratory samples, Ziehl-Neelsen stain and culture of mycobacteria, silver stain to detect P. jirovecii, and PCR to identify the presence of other respiratory viruses, were collected. For the diagnosis of CMV, viral culture of bronchoalveolar lavage (BAL) and CMV detection by real-time quantitative PCR (Q-CMV Real Time, Nanogen) in plasma, BAL and / or biopsy of the affected organ, were performed.

\section{Statistical analysis}

Categorical variables were expressed as frequencies and percentages, and continuous variables were expressed as mean and standard deviation. Results were considered statistically significant if the p-value was less than 0.05 . To evaluate the relationship between quantitative variables, T-test for independent samples was used in normally distributed variables and U-Mann Whitney in those not normally distributed. The chi-squared was used to evaluate the relationship between qualitative variables. All statistical analyses were calculated using SPSS version 20.0 (Chicago, IL, USA).

\section{RESULTS}

56 HIV-infected patients were identified with AICMV. The mean age was 43 years, $44(79 \%)$ were male, and $6(11 \%)$ had HCV coinfection. HIV transmission was through sexual contact for 48 (88\%) patients and IDUs (drug abuse) for 8 (22\%). Only 15 (27\%) were receiving cART. The median CD4 count was 31 cells/ $\mu$ l (IRQ = 61), HIV VL 284050 copies / ml (IRQ $=631,625)$, the average blood CMV VL was $68569.94 \pm 26718,5$ copies / $\mathrm{ml}$, and in BAL, $3359.0 \pm 47985,93$ copies / $\mathrm{ml}$. Nineteen $(34 \%)$ patients were admitted to ICU. The most common clinical sign was fever (59\%). The other variables are shown in table 1.

Out of the 56 patients who had AICMV, $34(61 \%)$ of them presented with RI, as a clinical manifestation, to the ED. The lower airways were always affected of which 31 (92\%) patients had pneumonia and 3 (8\%) had pulmonary tuberculosis (TB). In 29 (85\%) patients, CMV coinfection was detected with other microorganisms: Mycobacterium tuberculosis in 3 (8\%), P. jirovecii in $21(68 \%)$, Haemophilus influenzae in $2(6 \%)$, Klebsiella pneumoniae in $1(3 \%)$, Pseudomonas aerouginosa in 1 (3\%), Streptococcus pneumoniae in 1 (3\%). In five (16\%) patients, CMV was the only pathogen isolated.(table 1). All patients diagnosed with pneumonia caused by P. jirovecii or TBC showed a degree of severe immunosuppression. In our series, no patient had acute retinitis or any other ophthalmic involvement and only 8 patients (14\%) presented with digestive symptoms. Others clinical manifestations are shown in table 2 .

The overall 30 -day mortality was $18 \%$ (10 patients) and $5(50 \%)$ of them had a respiratory infection, $2(12 \%)$ had an infection of the central nervous system (cerebral toxoplasmosis), 1 (6\%) died from liver failure (HCV coinfected patient), 1 (6\%) from hematologic disease (lymphoma) and $1(6 \%)$ from intestinal infection (lamblia giardiasias). Death from respiratory infection, compared to the total sample, occurred in five patients (9\%): in 3 (60\%) cases due to pneumonia by $\mathrm{P}$. jirovecii, in 1 (20\%) by $\mathrm{H}$. influenzae and in $1(20 \%)$ by S. pneumoniae. The only variables associated with mortality were: the need for ICU admission $(\mathrm{X} 2=17.7 ; \mathrm{p}<0.001)$ and the need for MV (X2 = 28.3; p <0.001) (table 3 ). The mortality rate for patients admitted to the ICU was $47 \%$.

The CMV viral load in the blood showed no discriminative power for mortality (30846.7 \pm 69235.8 vs. $2100034.8 \pm 573143.6$; $\mathrm{U}=84 ; \mathrm{p}=0.197$ ), while the viral load in BAL was significantly higher in patients who died $(103648.0 \pm 40658.7$ vs 9929.3 $\pm 16066.3 ; \mathrm{U}=12 ; \mathrm{p}=0.208)$.

Table1. Descriptive analysis of the HIV and active infection by cytomegalovirus (AICMV) population.

\begin{tabular}{ll}
\hline Age (mean) & 43 \\
\hline Male (\%) & $44(79 \%)$ \\
\hline ART $(\%)$ & $15(27 \%)$ \\
\hline HCV Co-infection (\%) & $6(11 \%)$ \\
\hline Drugs (\%) & $9(16 \%)$ \\
\hline CD4 (median) cel/ $\mu \mathrm{l}$ & $31 \mathrm{cel} / \mu \mathrm{l}(\mathrm{IRQ}=61)$ \\
\hline HIV Viral load (mean) copies/ml & $284050 \mathrm{copies} / \mathrm{ml}(\mathrm{IRQ}=631625)$ \\
\hline Previous opportunistic infection $(\%)$ & $15(27 \%)$ \\
\hline ICU admission $(\%)$ & $19(34 \%)$ \\
\hline
\end{tabular}




\begin{tabular}{|c|c|}
\hline Mechanical ventilation (\%) & $12(21 \%)$ \\
\hline Overall mortality (\%) & $10(18 \%)$ \\
\hline Fever $(\%)$ & $33(59 \%)$ \\
\hline Associated comorbidities (\%) & $20(36 \%)$ \\
\hline Mortality from respiratory infection (\%) & $5(9 \%)$ \\
\hline CMV viral load in blood & 11,15 copies $/ \mathrm{ml}(\mathrm{IRQ}=85.24)$ \\
\hline CMV viral load in BLA & 66 copies/ml (IRQ=1466.9) \\
\hline Sexual trasmission (\%) & $48(88 \%)$ \\
\hline Respiratory isolations (\%) & $34(61 \%)$ \\
\hline Pneumocystis jirovencii & $21(68 \%)$ \\
\hline Haemophilus influenzae influenzae & $2(6 \%)$ \\
\hline Klebsiella pneumoniae & $1(3 \%)$ \\
\hline Pseudomona aerouginosa & $1(3 \%)$ \\
\hline Streptococcus pneumoniae & $1(3 \%)$ \\
\hline$\underline{\mathrm{CMV}}$ & $5(16 \%)$ \\
\hline Mycobacterium tuberculosis & $3(9 \%)$ \\
\hline
\end{tabular}

ART, Antiretroviral therapy; BAL, bronchoalveolar lávage; ICU, Intensive care unit; HCV, Hepatitis C virus.

Table 2. Active infection by cytomegalovirus (AICMV) clinical manifestations.

\begin{tabular}{ll}
\hline Respiratory (n) & $34(61 \%)$ \\
\hline Digestive (n) & $8(14 \%)$ \\
\hline Neurological (n) & $8(14 \%)$ \\
\hline Dermatological (n) & $2(3 \%)$ \\
\hline Hematological (n) & $3(5 \%)$ \\
\hline Ophthalmic (n) & $0(0 \%)$ \\
\hline Cardiological (n) & $1(2 \%)$ \\
\hline
\end{tabular}

Table 3. Predictors of mortality.

\begin{tabular}{|c|c|c|c|c|c|}
\hline \multicolumn{6}{|c|}{ Qualitative Variables and Mortality } \\
\hline \multicolumn{3}{|l|}{ VARIABLE } & Association & $\mathrm{CHI}^{2}$ & $\mathrm{P}$ \\
\hline \multicolumn{3}{|l|}{ Gender } & No & 0.902 & 0.761 \\
\hline \multicolumn{3}{|l|}{ ART } & No & 2.597 & 0.107 \\
\hline \multicolumn{3}{|l|}{ HIV transmission } & No & 1.141 & 0.285 \\
\hline \multicolumn{3}{|l|}{ HCV coinfection } & No & 0 & 1 \\
\hline \multicolumn{3}{|l|}{ Comorbidities } & No & 0 & 1 \\
\hline \multicolumn{3}{|l|}{ Smoker } & No & 0 & 1 \\
\hline \multicolumn{3}{|l|}{ Drugs } & No & 0.221 & 0.638 \\
\hline \multicolumn{3}{|c|}{ Opportunistic infections } & No & 1.936 & 0.164 \\
\hline \multicolumn{3}{|l|}{ ICU admission } & YES & 17.7 & $<0.001$ \\
\hline \multicolumn{3}{|c|}{ Mechanical ventilation } & YES & 28.3 & $<0.001$ \\
\hline \multicolumn{3}{|l|}{ Fever } & $\mathrm{NO}$ & 0.071 & 0.965 \\
\hline \multicolumn{3}{|c|}{ Clinical manifestations } & $\mathrm{NO}$ & 0.078 & 0.781 \\
\hline \multicolumn{6}{|c|}{ Quantitative Variables and Mortality } \\
\hline & MORTALITY & $\mathrm{N}$ & Median & IQR & $\mathrm{p}$ \\
\hline CD4 lymphocytes & YES & 10 & 82.2 & 54 & 0.672 \\
\hline No & 46 & 114.6 & 60 & & \\
\hline
\end{tabular}




\begin{tabular}{|c|c|c|c|c|c|}
\hline CD8 lymphocytes & YES & 10 & 540.4 & 633 & 0.482 \\
\hline No & 46 & 710.7 & 534 & & \\
\hline Viral load VIH & YES & 10 & 1889327.1 & 894828.0 & 0.549 \\
\hline No & 46 & 850621.2 & 610775 & & \\
\hline$\% \mathrm{CD} 4$ & YES & 10 & 11.3 & 9.0 & 0.278 \\
\hline No & 46 & 8.1 & 6.2 & & \\
\hline$\% \mathrm{CD} 8$ & YES & 10 & 64.5 & 15.3 & 0.702 \\
\hline No & 46 & 62.4 & 24.3 & & \\
\hline Leukocytes & YES & 10 & 6890.0 & 2950 & 0.854 \\
\hline No & 46 & 7236.5 & 490 & & \\
\hline Hemoglobin & YES & 10 & 11.4 & 3.15 & 0.753 \\
\hline No & 46 & 11.6 & 2.6 & & \\
\hline Platelets & YES & 10 & 225800.0 & 162500 & 0.536 \\
\hline No & 46 & 330413.0 & 196750 & & \\
\hline GOT & YES & 10 & 44.0 & 60 & 0.738 \\
\hline No & 45 & 49.0 & 36 & & \\
\hline Direct bilirubin & YES & 9 & 0.5 & 0.6 & 0.080 \\
\hline No & 45 & 0.2 & 0.1 & & \\
\hline GPT & YES & 10 & 26.0 & 15 & 0.269 \\
\hline No & 46 & 46.5 & 29 & & \\
\hline GGT & YES & 10 & 114.5 & 110 & 0.995 \\
\hline No & 39 & 114.0 & 42 & & \\
\hline LDH & YES & 10 & 856.5 & 546 & 0.622 \\
\hline No & 42 & 778.8 & 643 & & \\
\hline
\end{tabular}

ART, Antiretroviral therapy; GGT, gamma glutamyl transpeptidase; GPT, glutamic-pyruvic transaminase; IQR, interquartile range; $\mathrm{LDH}$, lactate dehydrogenase; OT, Glutamic oxaloacetic transaminase; ICU I, Intensive care unit; HCV, hepatitis C virus.

\section{DISCUSSION}

Lower respiratory tract infection is the most common infection in HIV-infected patients, and sometimes it is the first clinical manifestation of infection. (10) Our study confirms this and adds that this is also the case in AICMV. Pneumonia was the most common presentation of respiratory infection (31 cases) and the most common cause was P. jirovecii, unlike what was described in the literature previously, where the main bacterial etiology remains mainly at the expense of S. pneumonia. (11) In our series, there were only four bacterial isolates and among them S. pneumoniae was the only one. This is due to the degree of severe immunosuppression in our patients who had not started ART (because being infected with HIV was unknown before admission to ED), or because they were in the first 6 months of treatment, where ART had not yet reached its maximum effectiveness. Pulmonary involvement with CMV infection in the form of pneumonitis has a similar presentation to the one with P. jirovecii infection, which can lead to confusion and errors in treatment. (12) The patients with TB did not show any mortality in our series. However, this information should be taken with caution because our sample size is very small. Recent World Health Organization (WHO) studies also show that TB is responsible for up to one quarter of deaths of HIV-infected patients, especially when the infection is advanced. $(13,14)$

The highest percentage of respiratory manifestations in HIV-infected patients with AICMV shows a change in clinical presentation. Until now, according to the data reported in the scientific literature, ocular and gastrointestinal manifestations are the ones seen most frequently. (15) In our series, despite the high number of patients with immunosuppression, it was surprising that no patient had retinitis, but this is consistent with previous studies that have shown a decrease in retinitis, caused by CMV, in the cART era. (16)

The overall mortality in this study was $18 \%$, and the leading cause of death was respiratory infection (9\%). Mortality was higher in patients admitted to the ICU, as in previous studies. (17) Our work contrasts with the findings of Lichtner et al. (18) where cardiovascular and neurological events, attributed to immune dysfunction due to HIV / CMV coinfection, were the leading causes of death. CMV is an immunomodulatory virus which favors the appearance of opportunistic diseases, and the vast majority of HIV patients have a coinfection at some point in their life, leading to increased activation of the immune system, even if they are on cART, (19) with a consequent increase in mor- 
bidity and mortality. Early identification of CMV infection can prevent the onset of opportunistic infections. Based on the above, we believe that detection should be early, requesting, if there is any suspicion, diagnostic tests in the same HED and BAL since, as we have seen, higher viral load of CMV in BAL leads to increased mortality.

\section{LIMITATIONS}

Among the limitations of our study we emphasize that this is a single-center, retrospective study based on laboratory confirmation of CMV infection with a small number of cases.

\section{CONCLUSION}

In HIV patients, respiratory infection is the most common manifestation of AI$\mathrm{CMV}$, and is caused by opportunistic microorganisms, resulting in a $9 \%$ mortality.

\section{REFERENCES}

1. Sanbonmatsu Gámez S, Ruiz MP, Navarro Marí JM. Infection by human cytomegalovirus. Enferm Infecc Microbiol Clin 2014;32:1522.

2. Komdewall MJ, Mollema L, Tchermieva I, Van der Klis F, Kroes AC, Qudesluys-Murphy AM, et al. Cytomegalovirus infection in the Netherlands: seroprevalence, risk factors, and implications. J Clin Virol 2015;63:53-8.

3. Bowen EF, Griffiths PD, Davey CC, Emery VC, Johnson MA. Lessons from the natural history of cytomegalovirus. AIDS 1996;10:S3741.

4. Crum NF, Riffenburg RH, Wegner S, Agan BK, Tasker SA, Spooner KM, et al. Comparisons of causes of death and mortality rates aamong HIV-infected persons: analysis of the pre-, early, and late HAART eras. J Acquir Defic Syndrom 2006;11:194-200.

5. Camón S, Perelló R, Escoda O, Escoda R, Aguilar N, Saubi N, et al. (2014) Reason for HIV Patients Consultation to the Emergency Department in the HAART Era: Incidence and Mortality. J AIDS Clin Res 5:340.

6. Perelló R, Escoda O, Camón S, Miró Ò, Castañeda M, Moreno A, et al. Changes in the etiology, incidence and prognosis of acute respiratory track infections, in human immunodeficiency virus patients. Enferm Infecc Microbiol Clin 2015;33:243-7.

7. Kotton CN, Kumar D, Caliendo AM, Asberg A, Chou S, Danziger-Isakov L, et al. Transplantation Society International CMV Consensus Group. Update international consensus guidelines on the management of cytomegalovirus in solid-organ transplantation. Transplantation 2013;96:333-60.

8. Torre-Cisneros J, Fariñas MC, Castón J.J, Aguado J.M, Cantisán S, Carratalá J, et al.GESITRA-SEIMC/REIPI recommendations for the management of cytomegalovirus infection in solid-organ transplant patients. Enferm Infecc Microbiol Clin 2011;29:735-58.

9. Bartlett JG, Breiman RF, Mandell LA, File TM Jr. Community acquired pneumonia in adults: guidelines for management. Clin Infect Dis 1998;26:811-38.

10. Ojha CR, Rijal N, Khagendra KC, Palpasa K, Kansakar P, Gupta BP, et al. Lower respiratory tract infections among HIV positive and control group in Nepal. Virus disease 2015;26:77-81.

11. Cilloniz C, Torres A, Polverino E, Gabarrus A, Amaro R, Moreno E, et al. Community-accquired respiratory infections in HIVinfected patients: microbioal aetiology and outcome. Eur Respir J 2014;43:1698-708.

12. Katsidzira L, Fana GT, Makunike-Mutasa R, Ferrand RA. Pneumomediastinum in an HIV-infected patient with cytomegalovirus pneumonitis. Int J STD AIDS 2011;3:179-80.

13. WHO fact sheet on tuberculosis (TB) [Online]. October 2015. Reviewed March 2016; Available from: URL:http://www.who.int/ mediacentre/factsheets/fs104/en/ Fact sheet N8104.

14. Hosseinipour MC, Bisson GP, Miyahara S, Sun X, Moses A, Riviere C, et al. Empirical tuberculosis therapy versus isoniazid in adult outpatients with advanced HIV initiating antiretroviral therapy (REMEMBER): a multicountry open-label randomised controlled trial. Lancet 2016;387:1198-209.

15. Podlasin RB. CMV infection in HIV-patients. Przegl Epidemiol 2007;61:629-37.

16. Whitcup SM. Cytomegalovirus retinitis in the era of highly active antirretroviral therapy. JAMA 2000;283:653-7.

17. Papazian L, Hraiech S, Lehingue S, Roch A, Chiche L, Wiramus S. Cytomegalovirus reactivation in ICU patients. Intensive Care Med 2016:42:28-37.

18. Lichtner M, Cicconi P, Vita S, Cozzi-Lepri A, Galli M, Lo Caputo S, et al. Cytomegalovirus coinfection is associated with an increased risk of severe non-AIDS-defining events in a large cohort of HIV-infected patients. J Infect Dis 2015;211:178-86.

19. Boulougoura A, Sereti I. HIV infection and immune activation: the role of coinfections. Curr Opin HIV AIDS 2016;11:191-200. 